N O T A

\author{
Juan Noemi \\ Profesor de Teología \\ Pontificia Universidad Católica de Chile
}

\title{
El porvenir de los católicos latinoamericanos. Una reflexión elemental
}

La presentación del libro titulado El porvenir de los católicos latinoamericanos que edita el Centro Manuel Larraín y que reúne el aporte de varios autores, me anima a compartir con ustedes una reflexión elemental que me sugiere el título y que espero pueda servir a contextualizar el significado y pretensión de esta publicación.

Referirse al porvenir de los católicos en Latinoamérica comporta no solo una referencia puntual al futuro sino que supone e implica una al pasado y el presente de la Iglesia en América Latina. Imposible atisbar el futuro sin hacer memoria del pasado y considerar el presente. En este caso, y sin ninguna posibilidad de ofrecer aquí una retrospectiva más exhaustiva, se pretende esbozar el significado de un acontecimiento decisivo en el pasado más próximo de la Iglesia Católica en América Latina. Nos referimos al Concilio Vaticano II.

En realidad, el Concilio Vaticano II a pesar de ser un concilio cuyos protagonistas fueron en su mayoría europeos, donde parece haber encontrado un mayor eco y una recepción más decisiva ha sido en América Latina. Es así como con posterioridad al Vaticano II la reflexión teológica en América Latina dejó de ser un artículo exclusivamente importado. Este hecho tiene una importancia no solo eclesial sino cultural de gran trascendencia. A diferencia de Europa donde parece haberse producido un vacío o receso teológico con posterioridad al concilio, entre nosotros, se desató inmediatamente un proceso de búsqueda y producción teológicas inéditas hasta entonces.

Más que su discurso explícito sobre la teología (1), es el contexto eclesial esencialmente referido al mundo en que se sitúa el Vaticano II, lo que potenciará el

(1) Las referencias explícitas del Vaticano II a la teología no son muchas. A la que más aluden los teólogos europeos es a la que se hace sobre la existencia de "un orden o jerarquía de las verdades de la doctrina católica" (U.R.11). En América Latina, sin embargo, las que más resonancia han encontrado se leen en Gaudium et Spes 62:" Aunque la Iglesia ha contribuido mucho al progreso de la cultura, consta por experiencia que no escasean a veces las dificultades de compaginar la cultura con la formación cristiana. Estas dificultades no dañan necesariamente la vida de fe, incluso pueden estimular la mente a una más exacta y profunda comprensión de aquella. Puesto que los más recientes estudios y hallazgos de las ciencias, de la historia y de la filosofía suscitan nuevos problemas, que arrastran consecuencias prácticas y reclaman nuevas investigaciones teológicas, Por otra parte, los teólogos, guardando los métodos y las exigencias de la ciencia sagrada, están invitados a buscar siempre un modo más apropiado de comunicar sus conocimientos a los hombres de su época; porque una cosa es el depósito mismo de la fe - o sea, sus verdades- y otra cosa es el modo de formularlas, conservando el mismo contenido... 
resurgimiento teológico del postconcilio en América Latina. Esto se plantea claramente en los párrafos introductorios de la Constitución pastoral sobre la Iglesia en el mundo actual. Sobre todo en Gaudium et Spes 4 hay un texto que se convertirá en un verdadero programa teológico en Latinoamérica: "es deber permanente de la Iglesia escrutar a fondo los signos de los tiempos e interpretarlos a la luz del Evangelio, de forma que, acomodándose a cada generación, pueda la Iglesia responder a las perennes interrogantes de la humanidad sobre el destino de la vida presente y futura y sobre la mutua relación de ambas. Es necesario, por ello, conocer y comprender el mundo en que vivimos, sus esperanzas, sus aspiraciones y el sesgo dramático que con frecuencia lo caracteriza".

La Asamblea General del Episcopado latinoamericano celebrada en 1968 en Medellín se establece en directa dependencia del Vaticano II y puede considerarse como una aplicación creativa del mismo a la realidad latinoamericana (2). Aunque en ninguno de los 16 documentos redactados en Medellín se refiere a la teología como tal, sin embargo, en todos ellos se la percibe como algo esencialmente relativo a una situación histórica concreta. Baste un ejemplo: "La fidelidad de la Iglesia a la revelación tiene que ser dinámica. La catequesis no puede, pues, ignorar en su renovación los cambios económicos, demográficos, sociales y culturales sufridos en América Latina. De acuerdo con esta teología de la revelación, la catequesis actual debe asumir totalmente las angustias y esperanzas del hombre de hoy, a fin de ofrecerle las posibilidades de una liberación plena, las riquezas de una salvación integral en Cristo, el Señor" (Catequesis, 6).

Ahora bien, a mi parecer, lo más decisivo de Medellín no está en haber puesto en el tapete el tema de la liberación como tal, sino en que por primera vez y de manera explícita, conscientemente, se considera la situación de América Latina, no más como accidente prescindible, sino como contenido y material propios de la reflexión teológica. Se trata de atender e "interpretar los signos de los tiempos" tal como estos se perfilan en América Latina, de atender a la situación espacio-temporal, histórica, en la que se inserta la Iglesia y la teología. Se motiva un quehacer y ejercicio teológicos situados y responsables de la realidad concreta y no al margen de la misma.

Hemos afirmado anteriormente que lo acontecido en la teología latinoamericana tiene una trascendencia no solo eclesial sino un significado cultural enorme.

Los que se dedican a las ciencias teológicas y filosóficas en los seminarios y universidades empénense en colaborar con los hombres versados en otras materias, poniendo en común sus energías y puntos de vista. La investigación teológica siga profundizando en la verdad revelada, sin perder contacto con su tiempo... es de desear que numerosos laicos reciban una buena formación en las ciencias sagradas, y que muchos de ellos se dediquen ex profeso a estos estudios...".

(2) Esta aplicación fue promovida por el mismo Pablo VI, quien pocos días antes de la clausura del concilio, el 24.11.65, con motivo del décimo aniversario de la constitución del Consejo Episcopal Latinoamericano, les hace presente y exhorta a los obispos latinoamericanos para que atiendan con lucidez a la situación histórica: "Estamos bien convencidos de que es necesario tener un concepto claro, porque toda solución que no tenga en la debida cuenta esta compleja realidad corre peligro de resultar inadecuada y hasta ineficaz". Junto con reconocer el "peso numérico notable en el seno de la comunidad católica del mundo", Pablo VI se atreve a denunciar "un estado de debilidad orgánica del catolicismo latinoamericano" y el deber de "alcanzar todavía su plena madurez de desarrollo". Insegnamenti di Paolo VI III, 657. 
Así como de un niño se dice en un momento que "entró en uso de razón", después de cinco siglos podría decirse que la Iglesia latinoamericana ha empezado a dar pruebas de "uso de razón", de que es capaz de pensar por sí misma. Ciertamente no se trata de pruebas de una madurez adquirida, pero sí del inicio de una nueva etapa de desarrollo. Se trata de un momento crítico, de crisis, y no es ofensivo compararlo con el que atraviesa un adolescente que necesita autoafirmarse al tomar conciencia de sí. Es un momento decisivo del futuro que requiere de gran lucidez para no ofuscarse ante los riesgos y peligros que encierra y tampoco encandilarse ante el dinamismo vital que comporta. En todo caso - y sirviéndonos todavía de la imagen empleada- así como el adolescente no puede retornar a la infancia, sino que sus posibilidades se juegan en adquirir la madurez, así también no es una alternativa viable el retrotraerse al estado en que se encontraba la teología latinoamericana con anterioridad al Vaticano II. La situación no es fácil porque el peligro de paralogizarse, ante los riesgos y desafíos, de tratar de detener un desarrollo y proceso iniciado y todo esto con la mejor de las intenciones, ha dejado de ser mera posibilidad.

El auge y despliegue que experimenta la reflexión teológica entre nosotros con posterioridad al Vaticano II no es casual ni fortuita. De manera directa está condicionada por la intuición pastoral y eclesiológica de quien lo convocara. Juan XXIII fue explícito al respecto (3) y su requerimiento de una Iglesia extrovertida y al servicio del mundo se tradujo en el imponerse de un horizonte abierto que proyecta un cristianismo concretamente católico, es decir, universal y según el todo. Así lo constatan dos eminentes teólogos. El cardenal I. Congar señala como "magnífico programa" planteado por la Constitución dogmática sobre la Iglesia "la incorporación de pueblos y culturas" como "realización de la catolicidad" (4). Karl Rahner anota como "interpretación teológica fundamental del C. Vaticano II" el constituir "la primera autoactualización magisterial de la Iglesia como Iglesia mundial" (der erste amtliche Selbstvollzug der Kirche als Weltkirche) (5). Para ambos teólogos la propuesta de universalidad y catolicidad que plantea el Vaticano II (6) constituye un desafío clave y señala un camino irrecusable y complejo. Baste aquí señalar que la universalidad de la que se trata no se debe confundir con uniformidad y recordar que la catolicidad para verificarse realmente no se impone desde fuera, sino debe ser expresión que conjuga la diversidad.

(3) En la apertura del Concilio, Juan XXIII proclama solemnemente que el concilio se justifica solo en un horizonte de apertura y extroversión de la Iglesia con respecto al mundo moderno: "En el cotidiano ejercicio de nuestro ministerio llegan, a veces, a nuestros oídos, hiriéndolos, ciertas insinuaciones de almas que, aunque con celo ardiente, carecen de sentido de la discreción y la medida. Tales son quienes en los tiempos modernos no ven otra cosa que prevaricación y ruina... se comportan como quienes no tienen nada que aprender de las historia... Nos parece necesario decir que disentimos de esos profetas de calamidades. Si la tarea principal del concilio fuera discutir uno u otro artículo de la doctrina fundamental de la Iglesia... para eso no era necesario un concilio...".

(4) "Propiedades esenciales de la Iglesia", en Mysterium Salutis IV, Madrid 1973, 510.

(5) "Theologische Grundinterpretation des II. Vatikanischen Konzils", en Schriften zur Theologie $X I V, 288$.

(6) Como lo explicita el mismo K.Rahner en Die bleibende Bedeutung des II.Vatikanischen Konzils, en Schriften zur Theologie XIV, 303-318. 
Consideremos ahora la situación que se ha producido con posterioridad al auge que tuvo la teología de la liberación en América Latina. No se trata ciertamente de hacer un balance pormenorizado de lo que ha sido el desarrollo de la teología latinoamericana con posterioridad al Concilio Vaticano II (7). Quisiera solo referirme brevemente a la situación que se ha producido en los últimos treinta años, en los cuales el hacerse patentes de los límites y carencias de la teología de la liberación podría malentenderse como un desenlace que sanciona la imposibilidad de un ejercicio teológico realmente inculturado en Latinoamérica. Con respecto a esto es preciso distinguir entre los límites y defectos reales de la teología de la liberación (8) y el aporte sustantivo que ella representa y el desafío pendiente que permanece como su fruto más perdurable.

Como ya lo señaláramos, la Conferencia del Episcopado latinoamericano celebrada en Medellín, en 1968, constituyó un evento decisivo en el desarrollo de la teología latinoamericana. Se trataba de determinar los específicos signos de los tiempos de la realidad latinoamericana. De esta manera, la vivencia y experiencia cristianas quedaban asumidas e integradas como un momento propio desde el cual debe surgir la reflexión iluminada por la fe, es decir, a la reflexión teológica se le abre una posibilidad inédita hasta entonces en nuestro medio: asumir la realidad latinoamericana no como periferia sino tema teológico.

Ahora bien, el nuevo horizonte que le abre Medellín a la teología en América Latina no fue el fruto de una reflexión hermenéutica elaborada con anticipación por teólogos latinoamericanos, sino un desafío que a estos les fue planteado por los obispos. Sin mayores mediaciones que el llamado de Medellín, América Latina se convertía en material de la misma reflexión teológica. Medellín representó un desafío enorme para los teólogos que lo captaron, con toda razón, como una exigencia surgida del mismo Concilio Vaticano II y asumida por el episcopado latinoamericano.

En una primera etapa este desafío de interpretación teológica de los signos de los tiempos se actualizó en atención a los aportes que era posible recoger de determinados análisis socioeconómico globales. Las teorías del desarrollo, de la marginalidad y de la dependencia permitían acceder a una visión general de la situación latinoamericana. Los conceptos de liberación, opresión, marginalidad, dependencia, etc., constituyen entonces verdaderas claves interpretativas, a través, de las cuales se accede a lo latinoamericano.

En un segundo momento empezaron a hacerse evidentes los límites de esta reflexión teológica mediada socioeconómica y políticamente. Las mencionadas claves hermenéuticas se perciben estrechas y demasiado esquemáticas para expresar la riqueza y complejidad del fenómeno histórico que representa América Latina. Algunos se han contentado en señalar como la única causa de la acriticidad con que se asumieron ciertos diagnósticos socioeconómicos, un interés ideológico y político subyacente.

(7) Al respecto me permito remitir a lo que señalo en La fe en busca de inteligencia, Santiago 1993, pp. 212-218.

(8) A los que, en un equipo de estudio, aludimos ya desde sus inicios. Ver F. Castillo, J. Noemi, J. Arteaga, E. Rodríguez, Teoría y praxis en la teología de la liberación, en Teología y Vida 15 (1974) 3-38. 
Las lagunas y la acriticidad con que se ha teologizado en América Latina, sin embargo, no tienen su única y exclusiva raíz en lo político. Tienen también una raigambre filosófica que suele pasar desapercibida. El problema teológico reside en que la filosofía no es un lujo para el teólogo, sino una necesidad que determina la seriedad y la misma posibilidad de su quehacer, y Latinoamérica no ha sido reflexionada filosóficamente. El teólogo no tiene como referente un discurso filosófico fundamental y crítico de Latinoamérica con el cual confrontarse y al cual recurrir.

De allí que el futuro de la teología en América Latina no se decide en la polémica entre liberacionistas y antiliberacionistas. Esta es una anécdota más en el penoso historial del reductivismo intelectual provocado por intereses políticos inmediatistas. El verdadero desafío es contructivo, creativo: pensar Latinoamérica, pensarla desde sus raíces.

Que el "ocaso" de la teología de la liberación pueda degenerar en la renuncia a una teología realmente inculturada en América Latina no sería posible si no existiera una carencia antecedente, un verdadero lastre histórico, un déficit contemplativo y reflexivo que estamos muy poco dispuestos a reconocer, y más bien, en aras de una burda apologética de la institución, tiende a mistificarse como algo positivo. Cuando Pablo VI al terminar el Concilio Vaticano II les hacía presente a los obispos latinoamericanos "un estado de debilidad orgánica" de nuestro catolicismo y llamaba a "que la fe del pueblo latinoamericano debe alcanzar todavía su plena madurez de desarrollo" (9), no se trata del clamor de un intelectual de escritorio, sino de la percepción de una pastor clarividente que sabe que la fe en Jesús como evangelio implica insoslayablemente pensarlo como logos y pensarse como receptores activos de este don. De hecho, la extroversión eclesial, consciente y explícitamente asumida en el Vaticano II, pretendió terminar con la impronta de introversión eclesial ante el mundo moderno determinada por Trento y el Vaticano I, y de hecho le abrió un espacio inédito al catolicismo latinoamericano para reflexionar sobre sí mismo, para asumir su propio espacio y tiempo como reales. Una primera muestra de ello fue precisamente el auge de la teología latinoamericana con posterioridad al último concilio ecuménico.

A la, todavía después de cinco siglos, incipiente recepción intelectual y reflexiva de Jesús como evangelio y logos de Dios, se se ha sumado un sopor reflexivo y un incremento de corrientes fundamentalistas al interior del catolicismo criollo que tratan de zafarse del cuestionamiento que representa la modernidad al cristianismo. Como bien lo sintetiza un autor: "Fundamentalismo es la salida autoculpable de las pretensiones del pensar propio, de la propia responsabilidad, de la obligación de fundamentar, de la inseguridad y de la apertura, de cualquier pretensión de validez, legitimación de poder y forma de vida, cuyo pensamiento y vida han sido expuestos de manera irreversible por la Ilustración y la Modernidad. Salida hacia la seguridad y armonía de fundamentos absolutos escogidos por uno mismo. Ante estos fundamentos, debe abstenerse cualquier cuestionamiento para que ellos puedan dar sostén absoluto. Ante ellos todo lo demás debe relativizarse, para que ellos puedan permanecer inmunes a la relativización. Quien no se establece a partir de tales fundamen-

(9) Insegnamenti di Paolo VI, III, 657. 
tos no merece ser tomado en cuenta en sus argumentos, dudas intereses y derechos" (10). No es el momento para explayarse (11) sobre la vigencia de corrientes fundamentalistas al interior del catolicismo latinoamericano. Baste recordar que se trata de una reacción religiosa tan espontánea como suicida para un católico. En realidad, el "sí' fundamental a la edad moderna" (12) que representa el Vaticano II en palabras de Benedicto XVI ha sido opacado por un desencantamiento generalizado sobre las posibilidades de la misma que hace de buen caldo de cultivo de las corrientes fundamentalistas. Sin embargo, sigue teniendo vigencia la sentencia pronunciada por un devoto pensador católico cuando arreciaba la reacción antimodernista: "si la religión renuncia a tener razón se suicida" (13).

Talvez más difundido que un explícito fundamentalismo es el síndrome de un emocionalismo difuso, es decir, el intento de refugiarse en una religiosidad íntima e intransitiva, en una espiritualidad afectiva y emotiva, en la gratificante vivencia de una salvación emocionalmente autosuficiente. Se olvida entonces que la fe es inseparable de la razón, que el creer tiene su condición de posibilidad en el pensar, en palabras de san Agustín que fides nisi cogitetur nulla est (la fe que no se piensa se anula) y consecuentemente que reconocerse como "discípulo y misionero de Jesucristo" comporta una inextirpable responsabilidad intelectual. En realidad, solo una Iglesia "intelectualmente habitable" (14) está en condiciones de evangelizar.

Concluyo con esta reflexión elemental que me sugiere el pasado próximo y el presente de nuestra Iglesia para así contextualizar el porvenir esperanzado al que, a mi parecer, apunta el libro editado por el Centro Manuel Larraín que hoy se presenta. Es un primer ensayo, al que esperamos sigan muchos más, en que se acoge el llamado de la $1^{\text {a }}$ Carta de Pedro $(3,15)$ : "Estad dispuestos siempre a dar razón de vuestra esperanza a todo el que os lo pida". Es también signo de nuestro compromiso con la misma y concreta Iglesia que amó don Manuel Larraín.

(10) T. Meyer, Fundamentalismus.Aufstand gegen die Moderne, Reinbeck 1989, 157.

(11) Como lo hago en La iglesia interpelada por la razón moderna. Una aproximación desde la situación latinoamericana, en Sociedad Chilena de Teología, La Iglesia interpelada, Santiago 1993 , 21-48.

(12) Discurso de Benedicto XVI a la Curia romana, en L'Osservatore romano (2005) N. 52, 11.

(13) L. de Grandmaison, "L'heure présente", en Christus: La réligion chrétienne 1932, 343. Citado en E. Poulat, Modernistica, París 1982, 17.

(14) F. von Hügel, Lettres à sa nièce, París 1964, 236. 